\title{
Decision Support System for Hyperspectral Remote-Sensing Data of Yellow River Estuary, China
}

\author{
Wang Ping, ${ }^{1}$ Jie Fu $\mathbb{D},{ }^{1}$ Wenyu Qiao, ${ }^{1}$ Muhammad Yasir $\left(\mathbb{D},{ }^{2}\right.$ Sheng Hui, ${ }^{2}$ \\ Md Sakaouth Hossain, ${ }^{3}$ and Shah Nazir $\mathbb{D}^{4}$ \\ ${ }^{1}$ College of Geodesy and Geomatics, Shandong University of Science and Technology, Qingdao 266590, China \\ ${ }^{2}$ College of Oceanography and Space Informatics, University of Petroleum Qingdao, Qingdao 266580, China \\ ${ }^{3}$ Department of Geological Sciences, Jahangirnagar University, Savar, Dhaka 1342, Bangladesh \\ ${ }^{4}$ Department of Computer Science, University of Swabi, Swab, Pakistan \\ Correspondence should be addressed to Jie Fu; jeff101@sdust.edu.cn and Shah Nazir; shahnazir@uoswabi.edu.pk
}

Received 23 August 2021; Accepted 8 October 2021; Published 27 October 2021

Academic Editor: Rahman Ali

Copyright ( $\odot 2021$ Wang Ping et al. This is an open access article distributed under the Creative Commons Attribution License, which permits unrestricted use, distribution, and reproduction in any medium, provided the original work is properly cited.

There are many wetland resources in the area where the Yellow River enters the sea. This area has good ecological and economic value. Therefore, wetlands are precious resources. The accuracy of traditional wetland classification methods is low (for example, based on the support machine method). In order to explore ways to improve the accuracy of wetland classification, this paper selected the wetland at the mouth of the Yellow River as the study area. And, we used the hyperspectral data of "Zhuhai No. 1" as the research data. Then, we used the logarithmic transformation method to enhance the spectral characteristics of remote-sensing images. Finally, we used Markov random field method (MRF) and support vector machine method (SVM) to finely classify the wetlands in the Yellow River estuary area. We used these experiments to explore wetland classification methods for hyperspectral data. The results showed that the settings of the coupling coefficient and the initial value in the Markov model had a greater impact on the classification results. We found that the best result was when the initial classification number is 50 and the coupling coefficient is 0.5 . Compared with the SVM classification method, the overall classification accuracy of our proposed method was improved by $3.9672 \%$, and the Kappa coefficient was improved by 0.042 .

\section{Introduction}

Wetland, known as the "kidney of the Earth," is one of the most important ecosystems in the world. Because they have important biogeochemical, hydrological, and ecological functions, they have high generation and considerable economic and ecological value [1-4], and they play a key role in mitigating floods and filtering sewage and providing important habitat for many plants and for animals, therefore, these systems can greatly affect the human living environment. However, in the past 50 years, after land cover changes in some areas, wetlands have been polluted and greatly reduced [5]. This deterioration of the wetland environment has caused obvious ecological consequences, including floods, droughts, biological loss, and land fragmentation $[6,7]$. Accurate and up-to-date information about the spatial distribution of wetlands is important to improve our understanding of ecosystem conditions and management implementation [8-10].

Traditional wetland surveys are difficult to obtain largescale wetland information. Remote sensing provides an effective tool for large-scale monitoring of wetland land cover changes [11-15]. Many remote-sensing images used for wetland classification and change detection, such as multispectral data, including Landsat, Sentinels, and World Views, Unmanned Aerial Vehicles, and Hyperspectral sensors have been frequently used for wetland classification in the past few years [16-26]. Wetland classification applications are developing, and many applications are shifting from low- and medium-resolution images to high-resolution images. Wetlands are characterized by complex and lush vegetation, which is usually difficult to map with traditional 
optical sensors. Hyperspectral data have been used for the review of wetland research. Hyperspectral data have been obtained using an imaging spectrometer and provide complete and continuous spectral information with a large number of narrow bands $(<10 \mathrm{~nm})$ in the range of $0.38-2.5$ meters. Hyperspectral images include tens to hundreds of narrow bands and continuous spectral contours of each pixel. It greatly increases the detailed information of vegetation and is widely used in wetland research due to its complex vegetation composition. Satellite, airspace, and handheld hyperspectral data have been successfully used for wetland mapping, wetland species identification, plant leaf chemistry research, wetland soil characteristics analysis, and other topics. Due to the advantages of hyperspectral sensors in the number of bands and resolution, hyperspectral sensors have been widely used in wetland classification for continuous reflectance of ground vegetation. Belluco et al. used multispace and hyperspectral data to map tidal swamps with complex geomorphology and ecological characteristics and found that compared with multispectral data, hyperspectral data can achieve better classification [27]. Barducci et al. [28] used space and aerial hyperspectral images and other optical sensor images to monitor wetland characteristics and assess biogeochemical characteristics in the coastal area of the San Rosso Natural Park in Italy. Wetland species identification hyperspectral sensors provide tens to hundreds of narrow bands, providing detailed wetland vegetation information. They greatly improve the identification of wetland vegetation types [29].

Estuarine wetland is an important kind of wetland ecosystem because the interaction between rivers, oceans, and land is complex and changeable [30]. The Yellow River Delta wetland is located on the coast of the Bohai Sea in the northeastern part of Shandong Province. The land meets the river and the sea. It has important ecological services, resource supply, and efficient environmental production [31]. Due to the unique environmental conditions, economic status, and ecological fragility of this wetland, it is an important research field for studying biodiversity conservation and the impact of climate change. With the increase of human activities in the Yellow River Delta, such as land development activities such as excessive reclamation, coastal engineering, and environmental pollution, the vulnerability of wetlands has also increased [32, 33], wetlands are degrading, and this degradation is irreversible in some cases. Therefore, ensuring regional economic development without compromising the integrity of the ecosystem is a major challenge facing mankind. In order to protect wetlands, it is of great practical value to strengthen the monitoring and analysis of wetland landscape dynamics and changes. The identification of wetland types and the correct interpretation of wetland area are crucial research goals. With the development of remote-sensing technology, satellite-based data now provide the advantages of short revisit time and good accessibility of historical data, both of which help to monitor changes in wetlands $[34,35]$. In recent years, many studies have investigated the landscape evolution of the Yellow River Delta [36]. For example, Zong et al. used the supervised classification and visual interpretation methods of the
Yellow River Delta satellite data in 1986, 1996, and 2006 to analyze the dynamic changes of landscape patterns to reveal the characteristics of these changes and their driving factors [37].

There are few studies on the classification of hyperspectral data of wetland in the Yellow River Delta, and the application of hyperspectral data is mostly based on the research of smallscale hyperspectral data abroad. The data preprocessing methods and classification methods of "Zhuhai No. 1 " have few references. Therefore, it is very necessary to explore different methods of wetland classification for the hyperspectral data of "Zhuhai No. 1." The traditional hyperspectral image classification method is to perform gray-scale statistics of various features on the image through training samples and then classify each pixel into the corresponding category by classification criteria, mainly using the spectral characteristics of the pixel for classification. However, research has found that pixels adjacent in spatial locations on the image have a high probability of belonging to the same category, especially in wetland vegetation distribution areas. Traditional classification methods do not make full use of this feature, so the classification results are usually not ideal. The biggest feature of the MRF-based classification method is that it considers the regional constraints between pixels. Because the study area is of various wetland types, the pixels that are adjacent in space on the image have a high probability of belonging to the same category. Wetland classification has great advantages. Therefore, this paper proposes to apply MRF to wetland classification in the study area, which broadens the ability of my country's hyperspectral satellite data application channels and also fully taps the potential of the "Zhuhai No. 1" data and makes use of the uniqueness of the data. The role provides the possibility to make it a powerful tool for wetland classification-related research.

1.1. Study Area. The mouth of the Yellow River is located in Dongying City, Shandong Province, adjacent to Laizhou Bay in the east and Bohai Bay in the north (Figure 1). At the mouth of the Yellow River, there is the Yellow River Mouth Eco-Tourism Area. The geographical location of the tourist area is roughly between $118^{\circ} 41^{\prime} \mathrm{E}$ and $119^{\circ} 16^{\prime} \mathrm{E}$ east longitude and between $37^{\circ} 40^{\prime} \mathrm{N}$ and $38^{\circ} 10^{\prime} \mathrm{N}$ north latitude. With an area of more than 1,500 square kilometers, it has the broadest, most complete, and youngest wetland ecosystem in the warm temperate zone in the world $[38,39]$. This paper takes the estuary wetland area within the tourist area as the main research area. The geographic coordinates are roughly between $119^{\circ} 00^{\prime} \mathrm{E} \sim 119^{\circ} 20^{\prime} \mathrm{E}$ east longitude and $37^{\circ} 33^{\prime} \mathrm{N} \sim 37^{\circ} 54^{\prime} \mathrm{N}$ north latitude, and the study area is about $900 \mathrm{~km}^{2}$. The Yellow River carries a large amount of sediment from the estuary into the Bohai Sea. It extends about 2 kilometers into the sea every year. The annual land is 13.8 square kilometers. It is known as the youngest land in China. The estuary of the Yellow River has abundant land resources. At the same time, the Yellow River estuary is the largest natural vegetation area of newly born wetlands along the coast of China. There are more than 393 species of plants 


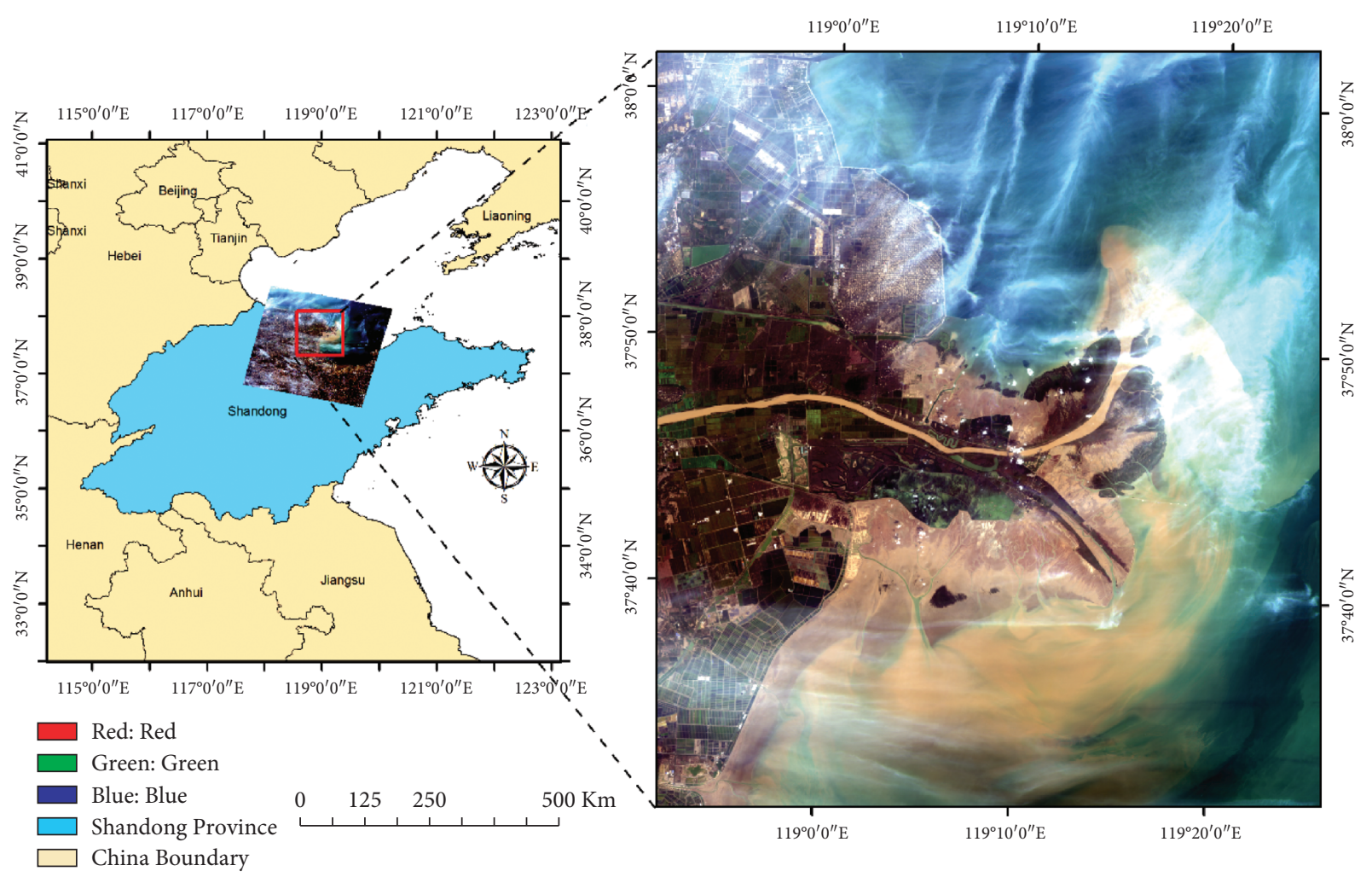

Figure 1: Geographical location of the study area.

in the region, including 277 species of wild seed plants. Representative species include tamarisk, reed, and Suaeda salsa [38].

\section{Materials and Methods}

\subsection{Database}

2.1.1. Remote-Sensing Data. The data source used in this article is "Zhuhai one" OHS hyperspectral satellite. Currently, the "Zhuhai-1" satellite has seven satellites in normal orbit. It is the only commercial hyperspectral satellite launched in China, and its characteristic of hyperspectral data are excellent [30]. The mass of OHS hyperspectral satellite is $67 \mathrm{~kg}$, the imaging range is $150 \mathrm{~km} \times 2500 \mathrm{~km}$, the number of spectral segments is 32 , the spectral resolution is $2.5 \mathrm{~nm}$, the spectral range is $400 \mathrm{~nm}-1000 \mathrm{~nm}$, and the orbit is $98^{\circ}$. Table 1 depicts details regarding the data.

2.1.2. Other Data. In order to establish a wetland classification system in the study area, it is necessary to select accurate training samples and ensure the accuracy and reliability of the classification results of the ground features. Therefore, it is necessary to conduct a field survey in the study area. This article is based on the collection and sorting of relevant data. The road map is shown in Figure 2.

The Yellow River Estuary wetland field survey was conducted in June 2019. We used GPS and cameras to record the site's category, location, and other attributes and took an overall landscape map of the sample. Each photo is associated with the corresponding location and shooting time. The association was established to facilitate subsequent reference and calculation. Table 2 shows the coordinates of the survey sample points and field photos.

According to the wetland classification principle, the classification system in the "Wetland Convention" and the "National Wetland Resource Survey and Monitoring Technical Regulations," combined with the field investigation in the study area, and the interpretable characteristics of the "Zhuhai No. 1" hyperspectral remote sensing image, we established a wetland classification system for the Yellow River estuary area. In order to explain the image characteristics of different wetland types systematically and improve the accuracy of subsequent sample selection. This study is based on the prior knowledge accumulated in the wetland survey carried out, as well as the spectral, texture, spatial location, and geometrical characteristics of different wetland types in the hyperspectral image, and established the classification and interpretation signs of the wetland types of the Yellow River estuary, and the basic image is a standard false color composite image. Refer to Table 3, for the interpretation signs of specific features.

The standard false color image is a composite image obtained by matching the near-infrared band to red, the red band to green, and the green band to blue.

The verification samples in this article are selected near each survey point in combination with the field survey and the collected classification maps of the study area. At the same time, in order to ensure the uniformity and sufficient quantity of the verification sample distribution, random 
TABLE 1: Brief introduction of Zhuhai No.1 hyperspectral data.

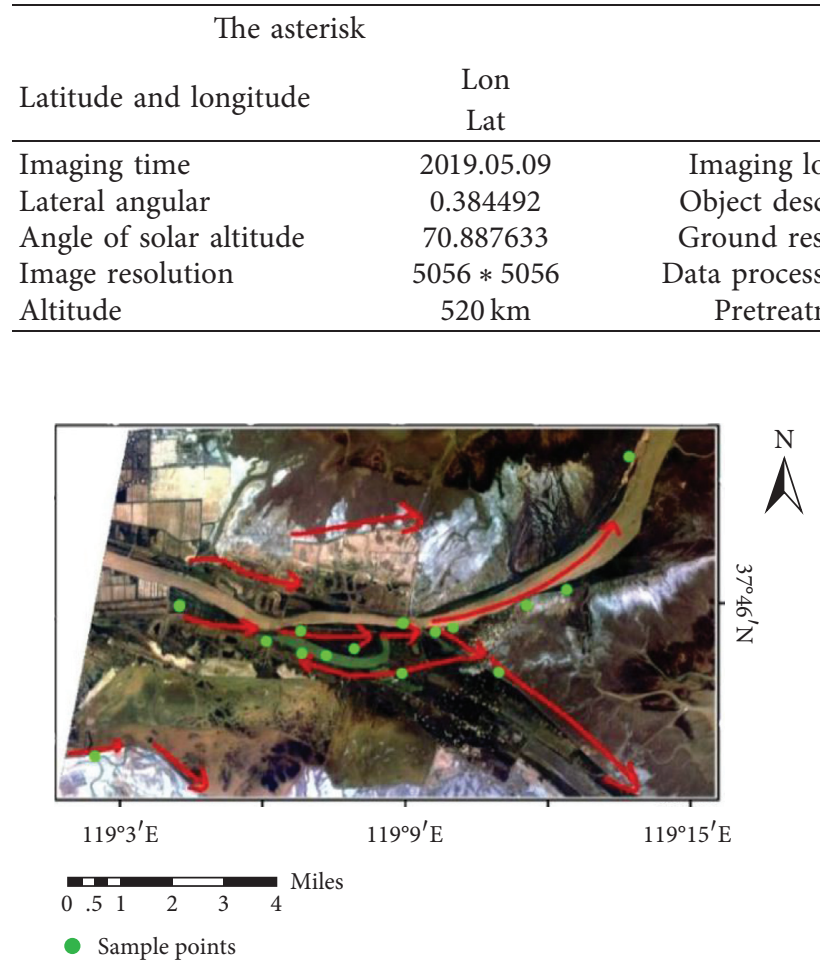

Figure 2: Survey route map.

points are generated in the study area, whose points are interpreted with the help of Google Earth as the verification sample. Finally, the number of verification samples is shown in Table 4.

2.2. Proposed Methodology. Aiming at the problem of "Zhuhai No. 1" hyperspectral remote-sensing image with a large number of bands and a very large amount of calculation, this article first transforms the "Zhuhai No. 1" hyperspectral image to enhance the spectral characteristics and then uses principal component analysis to analyze the image. Perform dimensionality reduction processing. Then, use Markov-based random field to classify the processed images and finally compare the classification results obtained with the classification results obtained based on the support vector machine classification method.

The steps of process used in the study are visualized in Figure 3.

2.2.1. Enhanced Spectral Features. The purpose of spectral feature enhancement is to facilitate the classification of the wetland in the study area. Based on this purpose, the variance has selected to measure the information content of the image because the variance can reflect the gray level of the image. The greater the value of variance, the more the levels are and the easier it is to identify features, and the distinguishability of features is also an important basis for feature enhancement.

Variance is the sum of squares of the difference between the pixel value and the average value:

$$
\sigma^{2}=\frac{\sum_{i=0}^{m-1} \sum_{j=0}^{n-1}[f(i, j)-\bar{f}]^{2}}{m n},
$$

where $\sigma^{2}$ is the variance, $m$ and $n$ are the number of rows and columns of the image, $f(i, j)$ is represented by the pixel value of the image, and $\bar{f}$ is the average pixel value of the image.

At the same time, the discriminant method of the classification of ground objects has selected to evaluate the transformed image. There are many methods to determine the distinguishability of surface features, such as Jeffreys-Matusita Distance (J-M distance), Bhattacharyya distance (B distance), dispersion, average distance between samples, and relative distance between categories. Compared with other indicators, J-M distance has considered more suitable for expressing category distinguishability [40]. $\mathrm{J}-\mathrm{M}$ distance is a spectral distinguishability index based on conditional probability theory, and equation (2) is as follows [39]:

$$
J_{i j}=\left\{\int_{X}\left[\sqrt{p\left(\frac{X}{\omega_{i}}\right)}-\sqrt{p\left(\frac{X}{\omega_{j}}\right)} \mathrm{d} X\right]\right\}^{1 / 2},
$$

where $J_{i j}$ is the distance between class $i$ and $j$ and $\sqrt{p\left(X / \omega_{i}\right)}$ is the conditional probability density, and it is the probability that the $i$ th pixel belongs to the $\omega_{i}$ th category. The value of $J_{i j}$ is between 0 and 2, and its size represents the degree of separation between samples.

2.2.2. Principal Component Analysis. There are many bands of hyperspectral images, which is conducive to the recognition of ground objects. Meanwhile, the large amount of data leads to information redundancy and complex data processing, which leads to time consumption and low accuracy of classification. In order to achieve a good balance between classification efficiency, accuracy, and applicability, features are usually extracted [41], that is, hyperspectral image data are processed with dimension reduction so that classification features can reach or even exceed the classification accuracy when the original features are reduced to a certain number [42]. In this article, principal component analysis (PCA) has been adopted to perform dimensionality reduction before classification of hyperspectral remotesensing images, therefore, to prepare for subsequent wetland classification.

PCA is the most basic dimensionality reduction method for hyperspectral data and plays an important 
TABLE 2: Coordinates and wetland photos of survey sample points in the study area.

\begin{tabular}{llll}
\hline The points & \multicolumn{1}{c}{ Coordinates } & Wetland types & The photographs \\
\hline 1 & $37^{\circ} 46^{\prime} 4.850^{\prime \prime} \mathrm{N} 119^{\circ} 04^{\prime} 7.150^{\prime \prime} \mathrm{E}$ & \\
3 & $37^{\circ} 45^{\prime} 43.63^{\prime \prime} \mathrm{N} 119^{\circ} 06^{\prime} 53.58^{\prime \prime} \mathrm{E}$ & \\
5 & $37^{\circ} 45^{\prime} 35.13^{\prime \prime} \mathrm{N} 119^{\circ} 08^{\prime} 27.38^{\prime \prime} \mathrm{E}$ & Reed wetland & \\
8 & $37^{\circ} 46^{\prime} 3.010^{\prime \prime} \mathrm{N} 119^{\circ} 09^{\prime} 55.32^{\prime \prime} \mathrm{E}$ & \\
9 & $37^{\circ} 46^{\prime} 32.75^{\prime \prime} \mathrm{N} 119^{\circ} 13^{\prime} 3.500^{\prime \prime} \mathrm{E}$ & \\
10 & $37^{\circ} 46^{\prime} 54.39^{\prime \prime} \mathrm{N} 119^{\circ} 12^{\prime} 29.49^{\prime \prime} \mathrm{E}$ & \\
\hline 2 & $37^{\circ} 45^{\prime} 43.57^{\prime \prime} \mathrm{N} 119^{\circ} 06^{\prime} 14.07^{\prime \prime} \mathrm{E}$ & Tamarisk wetland \\
4 & $37^{\circ} 45^{\prime} 41.59^{\prime \prime} \mathrm{N} 119^{\circ} 07^{\prime} 49.99^{\prime \prime} \mathrm{E}$ & \\
6 & $37^{\circ} 45^{\prime} 38.87^{\prime \prime} \mathrm{N} 119^{\circ} 09^{\prime} 37.58^{\prime \prime} \mathrm{E}$ & & \\
11 & $37^{\circ} 46^{\prime} 43.60^{\prime \prime} \mathrm{N} 119^{\circ} 11^{\prime} 46.76^{\prime \prime} \mathrm{E}$ & & \\
\hline
\end{tabular}
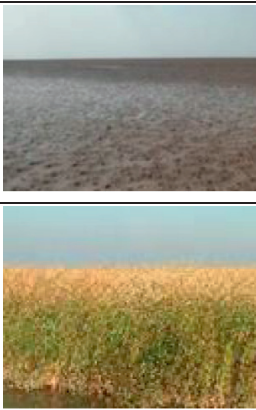

role in hyperspectral data compression, denoising (remove image noise), and feature extraction. After principal component transformation of hyperspectral images, each component is independent of each other and the information content decreases with each component in turn. Most of the information is mainly concentrated in the first few principal components. The specific reasoning of principal component transformation is as follows.

Suppose a multidimensional vector matrix $X=\left[x_{1}, x_{2}, \ldots, x_{p}\right]^{T}$ of $P \times N$ that the mean vector is $E(X)=0$ and the covariance matrix is $D(X)=\sum$, and the linear transformation of the matrix $X$ is performed:

$$
Z=A X=\left[\begin{array}{c}
z_{1} \\
z_{2} \\
\cdots \\
z_{p}
\end{array}\right]=\left[\begin{array}{c}
a_{1}^{T} X \\
a_{2}^{T} X \\
\cdots \\
a_{p}^{T} X
\end{array}\right]=\left[\begin{array}{c}
a_{11} x_{1}+a_{21} x_{2}+\cdots+a_{p 1} x_{p} \\
a_{12} x_{1}+a_{22} x_{2}+\cdots+a_{p 2} x_{p} \\
\cdots \\
a_{1 p} x_{1}+a_{2 p} x_{2}+\cdots+a_{p p} x_{p}
\end{array}\right],
$$

where the matrix $A=\left[a_{1}, a_{2}, \ldots, a_{p}\right]$ represents the transformation matrix and matrix $Z=\left[z_{1}, z_{2}, \ldots, z_{p}\right]^{T}$ represents the matrix obtained after linear transformation of matrix $X$; then, the variance matrix and covariance matrix of each vector in matrix $Z$ are as follows: 
TABLE 3: Interpretation of wetland features in the Yellow River Estuary.

\begin{tabular}{|c|c|c|c|}
\hline $\begin{array}{l}\text { Types of wetland } \\
\text { features }\end{array}$ & $\begin{array}{l}\text { Hyperspectral interpretation } \\
\text { logo: standard false color }\end{array}$ & Image feature & The scene photos \\
\hline Reed wetland & & $\begin{array}{l}\text { It is bright red, distributed naturally and evenly, and mainly } \\
\text { distributed on both sides of the river }\end{array}$ & \\
\hline Tamarisk wetland & & $\begin{array}{c}\text { It has dark red, uneven tone, and more scattered } \\
\text { distribution }\end{array}$ & \\
\hline Alkaline wetland & & $\begin{array}{l}\text { The color is light red, the hue is more uniform, and it is } \\
\text { distributed in the area with higher saline-alkali degree }\end{array}$ & \\
\hline $\begin{array}{l}\text { Interfloral rice- } \\
\text { grass wetland }\end{array}$ & & $\begin{array}{l}\text { It is dark red in color, has a uniform tone, and is distributed } \\
\text { near the sea }\end{array}$ & \\
\hline Turbid water & & $\begin{array}{l}\text { It is light yellow with uniform color and distributed in the } \\
\text { Yellow river and the southern sea area }\end{array}$ & \\
\hline Clear water & & $\begin{array}{l}\text { It is blue and black in color, with uniform image structure } \\
\text { and uniform tone, and distributed in shallow waters }\end{array}$ & \\
\hline Tidal flats wetlands & & $\begin{array}{c}\text { It is gray in color and has uniform distribution and coastal } \\
\text { distribution }\end{array}$ & \\
\hline Saline-alkali land & & $\begin{array}{l}\text { It is white in color and evenly distributed in the inland of } \\
\text { tidal flat wetland }\end{array}$ & \\
\hline
\end{tabular}

TABLE 4: Number of verification samples.

\begin{tabular}{lcc}
\hline The serial number & Wetland category & Number of validation samples \\
\hline 1 & Interfloral rice-grass wetland & 57 \\
2 & Tamarisk wetland & 26 \\
3 & Reed wetland & 49 \\
4 & Alkaline wetland & 40 \\
5 & Turbid water & 324 \\
6 & Tidal flats wetlands & 207 \\
7 & Saline-alkali land & 82 \\
8 & Clear water & 221 \\
10 & Total & 1006 \\
\hline
\end{tabular}




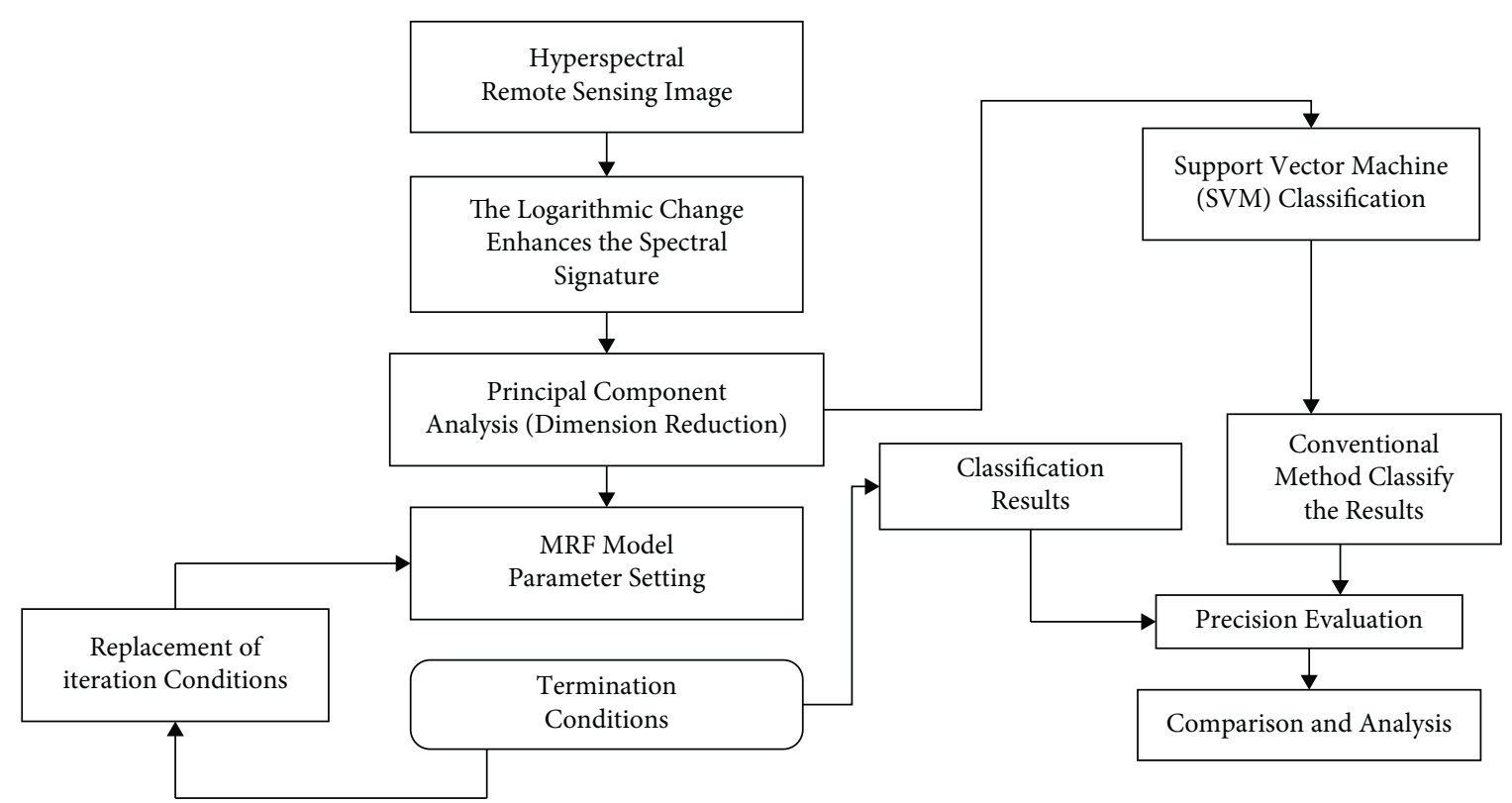

Figure 3: Schematic diagram of fine classification of the Yellow River estuary wetland based on hyperspectral data.

$$
\begin{aligned}
\operatorname{Var}\left(z_{i}\right) & =a_{i}^{T} \sum a_{i}, \quad i=1,2, \ldots, p, \\
\operatorname{Cov}\left(z_{i}, z_{j}\right) & =a_{i}^{T} \sum a_{j}, \quad i, j=1,2, \ldots, p .
\end{aligned}
$$

The idea of principal component transformation is that the first principal component can include most of the information in matrix $X$ after transformation. In general, variance is used to represent information, that is, $\operatorname{Var}\left(z_{i}\right)$ is required to be the largest, and $a_{1}^{T} a_{1}=1$. If such $z_{1}$ exists that $\operatorname{Var}\left(z_{1}\right)$ can be maximized, $z_{1}$ is the first principal component. To solve the second principal component, the $z_{2}$ information does not contain $z_{1}$ information, namely, $\operatorname{Cov}\left(z_{2}, z_{1}\right)=a_{2}^{T} \sum a_{1}=0$. In the rest of the vector, $\operatorname{Var}\left(z_{2}\right)$ is the largest. In addition, by analogy, we can figure out the remaining principal components.

2.2.3. Markov Random Airport Model (MRF). The theoretical basis of Markov random field is the MRF model and Bayesian theory, in which the MRF model adopts statistical decision and estimation theory to solve the uncertainty problem described by it. Markov random field algorithm transforms image classification problem into energy optimization problem [43]. Bayesian theory has been used to transform the prior knowledge of images into a prior distribution model for description, an objective function has been obtained for image classification according to the optimal criteria of estimation theory and statistical decision, and image classification has been realized by solving the maximum possible distribution satisfying these functions.

Markov random field uses the undirected graph model to express the relationship between variables and the overall effect, and the interaction between pixels is propagated through an undirected graph. In Markov random field, the interaction between variables and the whole can be described by undirected graph model, and it can also be used to describe the interaction between pixels in the image. The random variables in Markov are represented as nodes in the undirected graph, and the interaction between the random variables is represented as edges in the undirected graph. The nodes in the undirected graph represent a series of random variables satisfying Markov property, and the edges represent the interdependence between these random variables [44]. The node subset with connecting edges between any two nodes in the undirected graph model has called a group. If $C$ is a group of the undirected graph model and no node joining the group can make it form a larger group, then $C$ has called the largest group of the undirected graph model. We set $X_{C}$ corresponding to the largest $C$ random variables; according to Gibbs distribution theory, the joint probability distribution $P(X)$ can be presented as a function of random variable on the $C$ bits $\psi_{C}\left(Y_{C}\right)$ product, as shown in equation (5); the process is also known as the probability of undirected graph model factorization [45]:

$$
P(X)=\frac{1}{z} \amalg_{C} \psi_{C}\left(Y_{C}\right)
$$

In equation (5), $Z$ is the normalization factor, and its calculation formula is as follows:

$$
Z=\sum_{C} \prod_{C} \psi_{C}\left(Y_{C}\right)
$$

For image $L$, according to Bayesian theory, the posterior distribution calculation equation of its classification label $X$ is as follows:

$$
P(X \mid I)=\frac{P(I \mid X) P(X)}{P(I)},
$$

where $P(I)$ represents the probability of the image, which is generally a constant obtained by statistics, $P(X)$ is the prior probability, and $P(I \mid X)$ is the conditional probability of 
image $I$ under a given classification tag $X$. Therefore, the image classification carried out by the Markov random field model is to solve the estimation of $X$ with the maximum of the posterior distribution $P(Y \mid X)$ :

$$
\widehat{X}_{\mathrm{MAP}}=\arg _{x} \max P(X \mid I) \propto P(I \mid X) P(X) .
$$

Assuming that the observed data are independent of each other, then

$$
P(I \mid X)=\prod_{C} P\left(i_{C} \mid x_{C}\right) .
$$

According to formulas (5) and (9), the prior probability of the category has been combined with the observation model to obtain the posterior probability as

$$
P(X \mid I) \propto e^{-H(X \mid I)},
$$

where $H(X \mid I)$ is an energy function:

$$
\begin{aligned}
H(X \mid I) & =-\sum_{C} \ln P\left(i_{C} \mid x_{C}\right)+\sum_{s \in S} V_{C}(X)+\sum_{C} \ln Z \\
& =-\sum_{C}\left[n P\left(i_{C} \mid x_{C}\right)+\sum_{r \in \eta C} V_{S}(r, C)-\ln Z\right],
\end{aligned}
$$

where $S$ represents the set of all groups. The first term is the likelihood energy term, which represents the contribution value of each pixel to the energy function. The second term is the neighborhood energy term, which has been used to regularize the classification. Image classification and Markov random field model are used for solving the energy function $H(X \mid I)$, the smallest solution $\widehat{X}[46]$.

2.2.4. Support Vector Machines (SVM). In this study, in order to verify the effectiveness of the proposed method, conventional classifiers were used to classify the dimensionless images of wetlands in the study area by using the same data source "Zhuhai One" hyperspectral data. In conventional classifier, SVM compared with other classifiers, the small sample, nonlinear, and high-dimensional pattern recognition of the obvious advantages, resolves the "dimension disaster" and "learning" and other issues largely. Many researchers have applied to the classification of hyperspectral remote-sensing images and obtained ideal effect [47-49]. The SVM classification method is adopted by this article in the Yellow River estuary wetland "number one" Capital zhuhai hyperspectral remote-sensing image classification. Then, the hyperspectral remote-sensing image classification methods based on the Markov random field model are compared. SVM has been proposed based on the theory of $\mathrm{VC}$ dimension in statistical learning and the principle of structural risk minimization [50]. The basic idea is as follows: in the linear case, the value range of the constraint conditions has been adjusted through the parameter relaxation variable, and the classification problem has been transformed into separating the two types of samples by finding the optimal classification hyperplane. In the nonlinear case, the coordinate of the high-dimensional space can be mapped by the low-dimensional space through

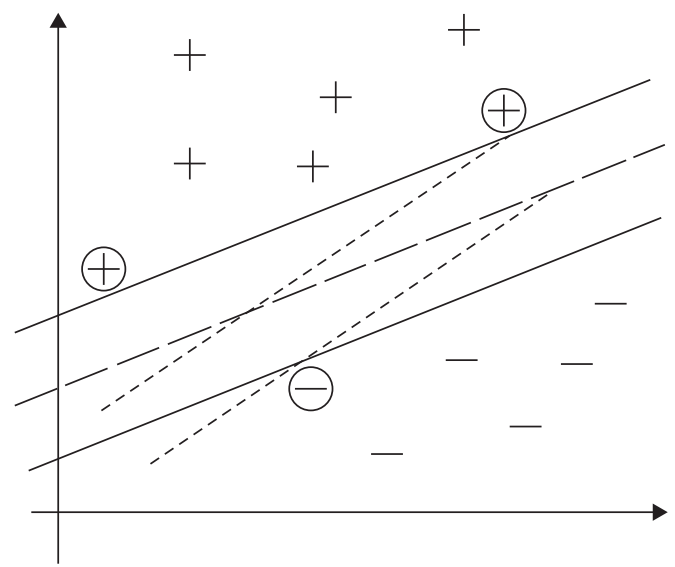

FIgURE 4: Rate of shoreline change (LRR in $\mathrm{m} / \mathrm{yr}$ ) for the year 2000 to 2019 .

the space transformation to the linear case. Therefore, the high-dimensional inner product should be transformed into the low-dimensional space by the kernel function, so as to find the optimal classification hyperplane [51].

Figure 4 is a schematic diagram of the optimal classification plane. There are two hyperplanes in the figure, one is a hyperplane between parallel solid lines and the other is a hyperplane between parallel dashed lines. Among them, the hyperplane between solid lines is the optimal hyperplane, whose classification interval is greater than that between two dashed lines [52].

2.2.5. Accuracy Verification. The verification point data are obtained through field investigation, and the overall classification accuracy, user accuracy, mapping accuracy, and Kappa coefficient are selected to evaluate the accuracy of the vegetation classification results of the hyperspectral image.

(i) Overall classification accuracy $(\mathrm{OA})$ : it refers to the probability that the classified results are consistent with the actual type of the corresponding area on the ground [53].

(ii) User accuracy (UA): it represents the ratio between the number of pixels correctly classified into category I of the entire image and the total number of category I pixels in the classification result.

(iii) Producer accuracy (PA): it refers to the ratio between the pixel number of the whole image correctly classified by the classifier as $j$ and the total number of true references of $J$ [53]

(iv) Kappa coefficient: the Kappa coefficient is mainly used to calculate the degree of similarity between two images and consider the classification accuracy by using statistics and probability principle

\section{Results and Discussion}

3.1. Spectral Feature Enhancement Result. In order to improve the classification accuracy, the images were transformed to improve stronger spectral information features, and the best 


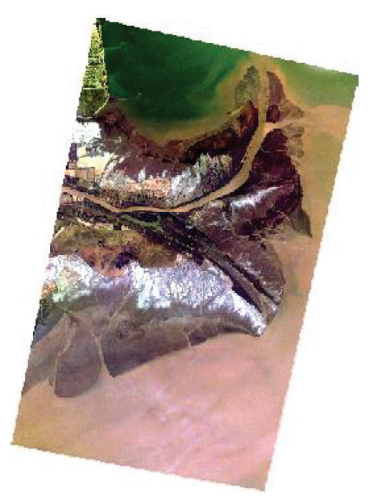

(a)

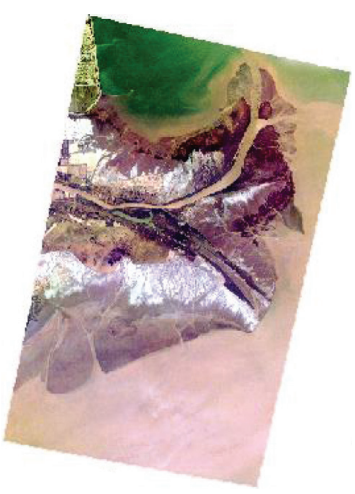

(b)

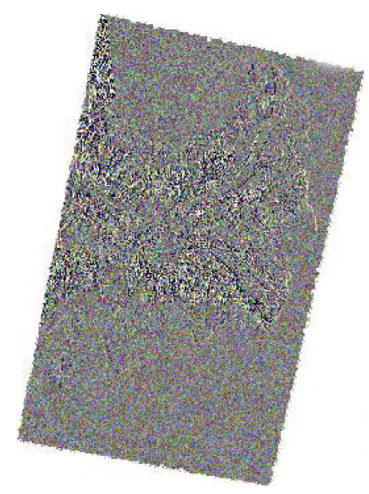

(c)

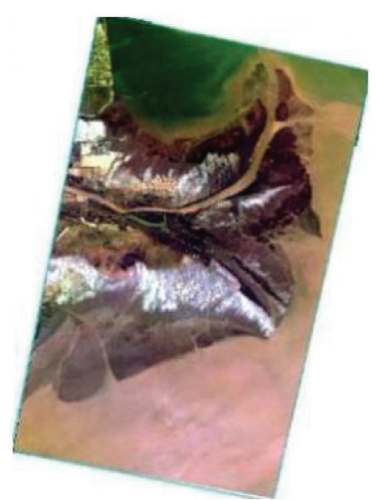

(d)

FIGURE 5: Comparison of images with enhanced spectral features: (a) original image; (b) image after derivative transformation; (c) image after exponential transformation; (d) image after logarithmic transformation.

TABLE 5: Variance values of the original image

\begin{tabular}{|c|c|c|c|c|c|c|c|}
\hline Band & Variance $\left(\times 10^{-3}\right)$ & Band & Variance $\left(\times 10^{-3}\right)$ & Band & Variance $\left(\times 10^{-3}\right)$ & Band & Variance $\left(\times 10^{-3}\right)$ \\
\hline 1 & 5.394 & 9 & 3.936 & 17 & 3.993 & 25 & 2.784 \\
\hline 2 & 4.99 & 10 & 4.038 & 18 & 4.463 & 26 & 2.687 \\
\hline 3 & 4.031 & 11 & 4.049 & 19 & 3.266 & 27 & 2.552 \\
\hline 4 & 2.997 & 12 & 4.242 & 20 & 2.901 & 28 & 2.618 \\
\hline 5 & 3.129 & 13 & 4.494 & 21 & 2.927 & 29 & 2.731 \\
\hline 6 & 3.309 & 14 & 4.703 & 22 & 2.89 & 30 & 2.881 \\
\hline 7 & 3.644 & 15 & 4.55 & 23 & 2.872 & 31 & 3.348 \\
\hline 8 & 3.818 & 16 & 3.702 & 24 & 3.161 & 32 & 3.844 \\
\hline
\end{tabular}

transformation processing method was selected. Figure 5 shows the comparison between the original image and the image after derivative, logarithmic, and exponential transformation. Tables 5-8 show the variance value of the original image and the image after spectral enhancement processing.

The analysis of the four kinds of data variance showed that the logarithmic image has the largest variance value, and the image gray level distribution is scattered, and the image contrast is large. All bands are equally divided. The logarithmic transformation can expand the bright area of the image, compress the dark area of the image, and make the variance of different bands different. Therefore, more information can be obtained after logarithmic transformation of the image, and the wetland features in the study area are easier to identify and classify.

$\mathrm{J}-\mathrm{M}$ distance was calculated and sorted for the above four image data. For the 8 species of wetlands in the study area, through comparative analysis, the separability of 4 planted wetlands in the three data was relatively poor. Table 9 shows the $\mathrm{J}$-M distances of different image data to vegetation wetlands.

It can be concluded from Table 9 that the separability of vegetation wetland is better in the logarithmic image compared to the original image and the image after derivative and exponential transformation.

The results are combined with the statistical results of the images and analyzed. The final method of spectral feature enhancement can be selected by the number method, which can enhance the transformation of wetlands in the study area and improve the separability of wetlands.

\subsection{MRF Model Coefficient Selection}

3.2.1. Principal Component Analysis. PCA can optimize the linear reconstruction error and is currently used in the feature extraction of hyperspectral images. This paper performs principal component transformation on the hyperspectral data of "Zhuhai No. 1" after logarithmic transformation. It can be concluded from Table 10 that the data of the first three principal components of the image after logarithmic transformation have $99.92 \%$ of the original data. Compared with the direct principal component analysis of the original image, the cumulative variance contribution rate has increased by $1.89 \%$. It can be seen that the logarithmic transformation of the image is conducive to the subsequent dimensionality reduction and classification research.

\subsubsection{Influence of Coupling Coefficient $\beta$ on Classification} Result. The coupling coefficient $\beta$ represents the strength of the action between the points within the potential group, also known as the smoothing coefficient, indicating the degree of punishment between adjacent pixel points, mainly to evaluate the smoothness of the image.

As the value of $\beta$ increases, the regional constraints between pixels increase, and spatial constraints are more and more taken into account in the classification process.

Figure 6 shows the classification results of hyperspectral images based on MRF with different coupling coefficients. 
TABLE 6: Variance values of the derivative image

\begin{tabular}{|c|c|c|c|c|c|c|c|}
\hline Band & Variance $\left(\times 10^{-3}\right)$ & Band & Variance $\left(\times 10^{-3}\right)$ & Band & Variance $\left(\times 10^{-3}\right)$ & Band & Variance $\left(\times 10^{-3}\right)$ \\
\hline 1 & 0.106 & 9 & 0.032 & 17 & 0.019 & 25 & 0.19 \\
\hline 2 & 0.09 & 10 & 0.027 & 18 & 0.024 & 26 & 0.18 \\
\hline 3 & 0.068 & 11 & 0.024 & 19 & 0.023 & 27 & 0.17 \\
\hline 4 & 0.052 & 12 & 0.024 & 20 & 0.02 & 28 & 0.15 \\
\hline 5 & 0.046 & 13 & 0.026 & 21 & 0.021 & 29 & 0.16 \\
\hline 6 & 0.045 & 14 & 0.03 & 22 & 0.02 & 30 & 0.17 \\
\hline 7 & 0.038 & 15 & 0.032 & 23 & 0.19 & 31 & 0.22 \\
\hline 8 & 0.035 & 16 & 0.022 & 24 & 0.19 & 32 & 0.38 \\
\hline
\end{tabular}

TABLE 7: Variance values of the logarithmic image

\begin{tabular}{lccccccc}
\hline Band & Variance $\left(\times 10^{-3}\right)$ & Band & Variance $\left(\times 10^{-3}\right)$ & Band & Variance $\left(\times 10^{-3}\right)$ & Band & Variance $\left(\times 10^{-3}\right)$ \\
\hline 1 & 1.229 & 9 & 0.95 & 1.123 & 18 & 1.869 & 25 \\
2 & 1.062 & 10 & 1.226 & 19 & 1.35 & 26 & 27 \\
3 & 0.854 & 11 & 1.296 & 20 & 1.259 & 28 & 1.121 \\
4 & 0.612 & 12 & 1.442 & 21 & 1.239 & 29 & 1.073 \\
5 & 0.678 & 13 & 1.625 & 22 & 1.246 & 30 & 1.147 \\
6 & 0.715 & 14 & 1.589 & 23 & 1.278 & 31 & 1.313 \\
7 & 0.816 & 15 & 1.269 & 24 & 1.469 & 32 & 1.588 \\
8 & 0.883 & 16 & & & & & 1.9 \\
\hline
\end{tabular}

TABLE 8: Variance values of the exponential image

\begin{tabular}{lccccccc}
\hline Band & Variance $\left(\times 10^{-3}\right)$ & Band & Variance $\left(\times 10^{-3}\right)$ & Band & Variance $\left(\times 10^{-3}\right)$ & Band & Variance $\left(\times 10^{-3}\right)$ \\
\hline 1 & 6.576 & 9 & 4.992 & 17 & 6.336 & 25 & 3.691 \\
2 & 5.801 & 10 & 5.452 & 18 & 6.491 & 3.765 & 26 \\
3 & 4.325 & 11 & 5.528 & 19 & 4.052 & 28 & 2.962 \\
4 & 2.953 & 12 & 5.994 & 20 & 3.722 & 29 & 3.171 \\
5 & 3.074 & 13 & 6.255 & 21 & 4.061 & 30 & 3.176 \\
6 & 3.336 & 14 & 6.539 & 23 & 4.253 & 3.424 \\
7 & 4.054 & 15 & 6.326 & 24 & 4.881 & 32 & 4.742 \\
8 & 4.528 & 16 & 5.219 & & & & 32 \\
\hline
\end{tabular}

TABLE 9: J-M distance of different image data on vegetation wetlands.

\begin{tabular}{|c|c|c|c|c|}
\hline Wetland category & Original image & Logarithmic image & Derivative images & Index of the image \\
\hline Interfloral rice-grass wetland: tamarisk wetland & 1.938 & 1.999 & 1.478 & 1.966 \\
\hline reed wetland: tamarisk wetland & 1.838 & 1.999 & 1.450 & 1.980 \\
\hline Alkaline wetland: tamarisk wetland & 1.913 & 1.999 & 1.547 & 1.998 \\
\hline Interfloral rice-grass wetland: reed wetland & 1.899 & 1.999 & 1.681 & 1.986 \\
\hline Interfloral rice-grass wetland: alkaline wetland & 1.952 & 1.999 & 1.509 & 1.973 \\
\hline Alkaline wetland: reed wetland & 1.916 & 2.000 & 1.713 & 1.952 \\
\hline
\end{tabular}

TABLE 10: Principal component analysis result.

\begin{tabular}{lccc}
\hline Image category & PC value & Eigenvalues & Percent eigenvalue (\%) \\
\hline \multirow{3}{*}{ Original image } & PC1 & 0.077 & 74.74 \\
& PC2 & 0.021 & 20.38 \\
\hline \multirow{3}{*}{ Logarithmic image } & PC3 & 0.003 & 3.03 \\
& PC1 & 0.087 & 83.63 \\
& PC2 & 0.016 & 15.39 \\
\hline
\end{tabular}




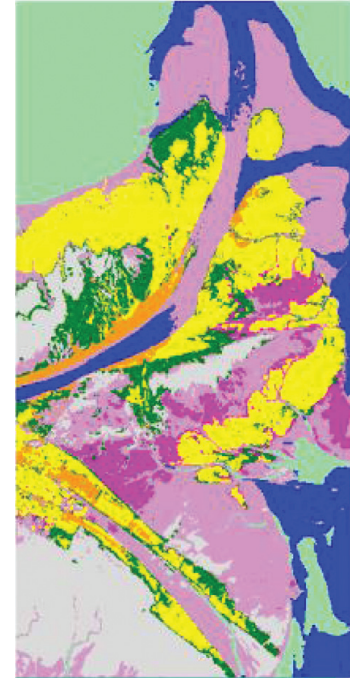

(a)

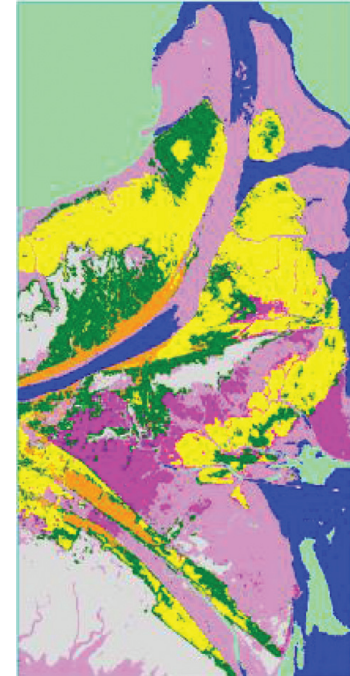

(b)

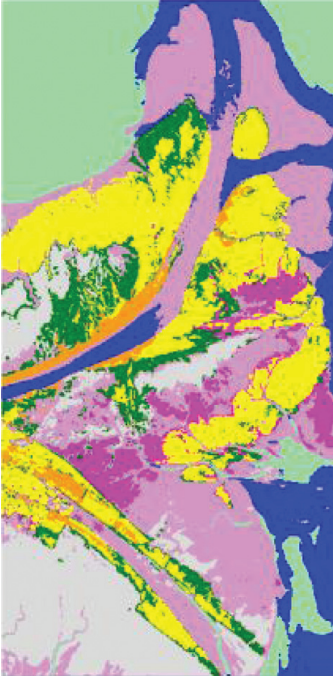

(c)

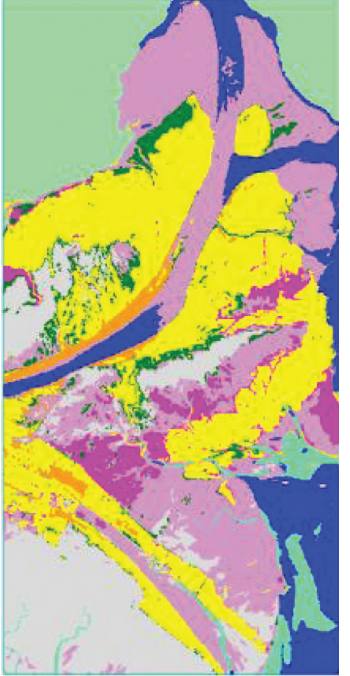

(d)

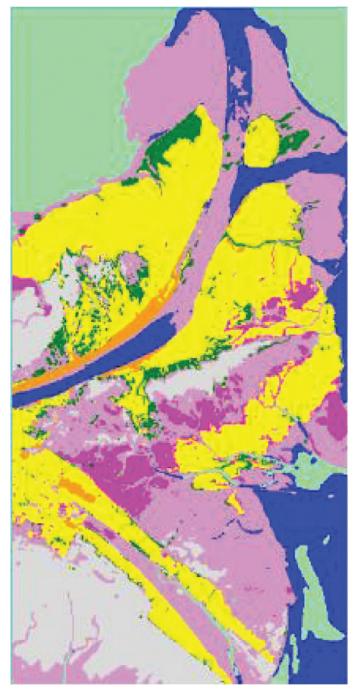

(e)

Figure 6: Classification results of hyperspectral images based on MRF with different coupling coefficients $\beta$. (a) $\beta=0.2$; (b) $\beta=0.5$; (c) $\beta=1.0$; (d) $\beta=2.0$; (e) $\beta=5.0$.

The coupling coefficient $\beta$ was used as a step size of 0.1 to analyze the variation of classification accuracy. From Figures 6 and 7, it can be concluded that, in the process of MRF classification, different coupling coefficients will have a certain influence on the final classification results of images. The comparative analysis showed that when the value of $\beta$ was small, the finer parts of the image could be detected and the edge contrast was large, but at the same time, there would be obvious pepper and salt phenomenon. With the increase of the coupling coefficient $\beta$ value, the pepper-salt phenomenon decreased, the regional continuity became better, and the classification accuracy was improved. However, some subtle areas with large changes will be missed. In summary, when the coupling coefficient $\beta$ value is small, the higher frequency information in the image can be better retained. In the classification results, the edge effect is better, but the corresponding salt and pepper phenomenon will occur, and the classification results have a large misclassification error. When the value of $\beta$ is large, the noise can be effectively suppressed so that the regional connectivity is good, but some high-frequency information will be ignored accordingly; then, the classification result leakage error is large. After the above experiments were analyzed, the coupling coefficient $\beta$ value of 0.5 was finally selected to classify the whole study area.

\subsection{Influence of Initial Value Selection on Classification Result.} In the MRF model, the selection of the initial value refers to the selection of the initial classification number. It shows that the classification results under the circumstances of different initial classification numbers in Figure 8.

Figure 9 describes the trend of classification accuracy under different initial categories. 


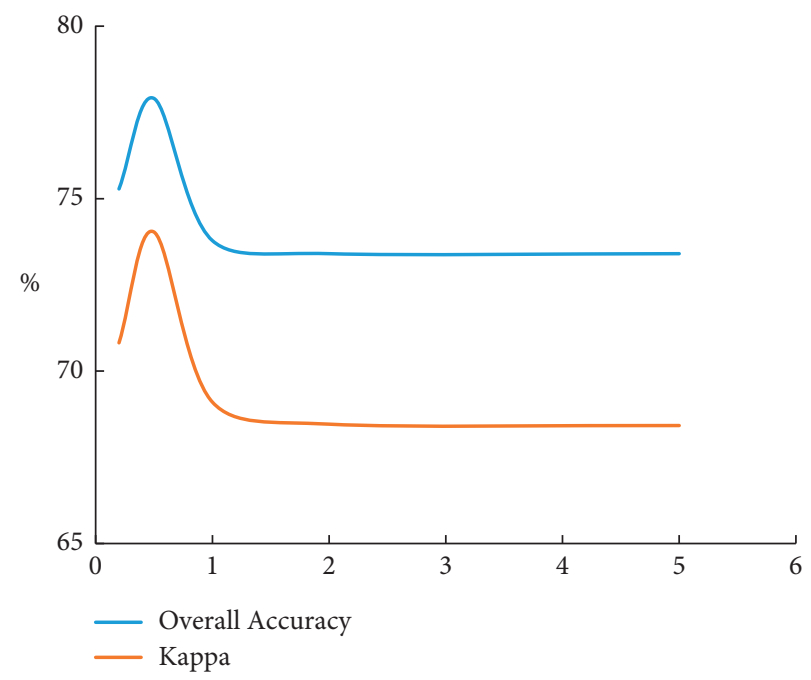

Figure 7: Trend of classification accuracy under different coupling coefficients $\beta$.

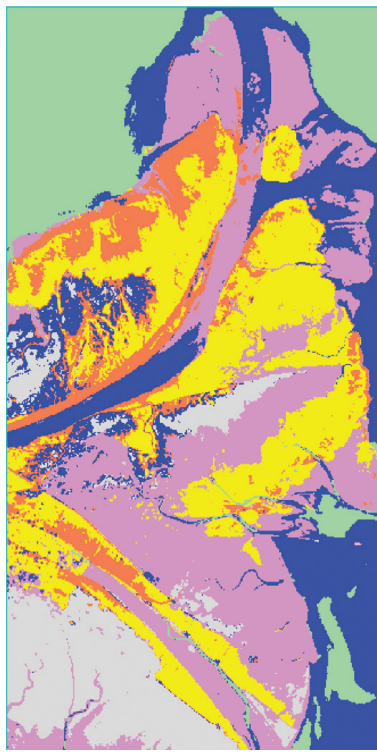

(a)

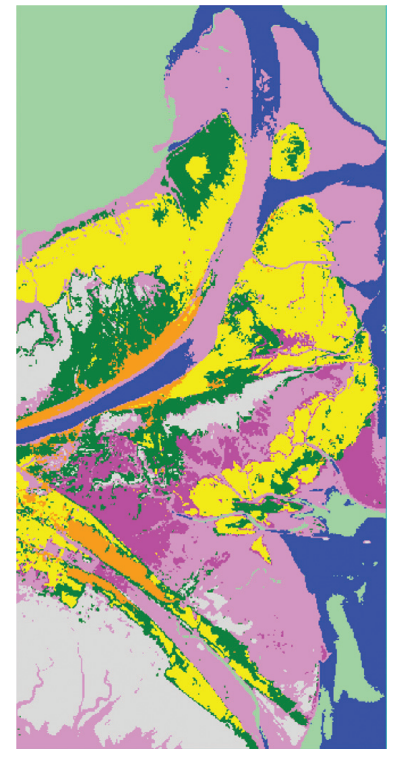

(b)

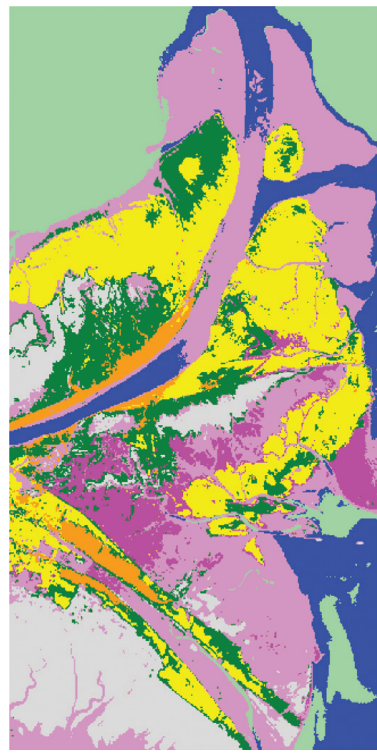

(c)

FIGURE 8: Hyperspectral image classification results based on the number of MRF initial categories. (a) Initial number of categories $=30$. (b) Initial number of categories $=50$. (c) Initial number of categories $=70$.

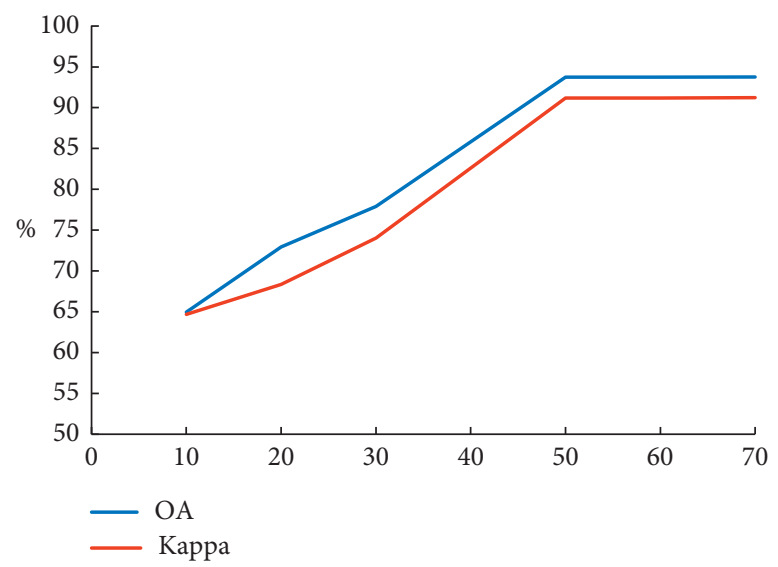

FIgURE 9: Trend of classification accuracy under different initial categories. 


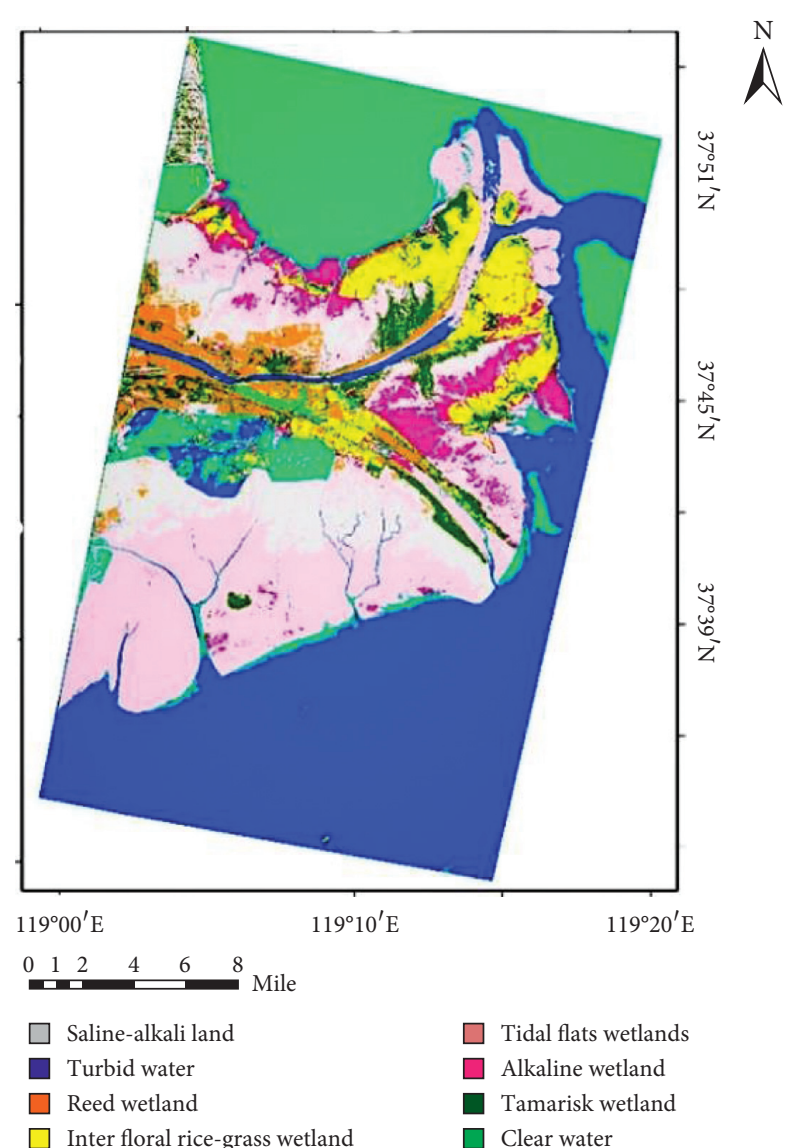

FIGURE 10: MRF-based classification result of hyperspectral remote-sensing images.

Through the above analysis, it can be concluded that the selection of the initial classification number has a great impact on the classification accuracy. When the number of initial categories is small, there will be more mixed classification and misclassification. As the initial number of categories increases, the classification becomes more detailed. It is found through experiments that the influence of the initial number of categories on the classification accuracy is also affected by the size of the study area. When the study area is large and the same number of initial categories is set, the classification accuracy will decrease, and with the continuous increase of initial categories, the time spent on classification will also increase. After the initial category 50, the classification accuracy decreases slightly and the growth is basically unchanged and the time is greatly increased, and the classification processing is more troublesome. Therefore, the initial category number is finally set as 50 for the research area in this paper after several experiments.

\subsection{Comparison of Classification Results}

3.4.1. Classification Result. After the logarithmic transformed image is processed by principal component analysis and dimension reduction, we use the MRF model and the SVM model to classify wetlands, and the results obtained are shown in Figures 10 and 11.

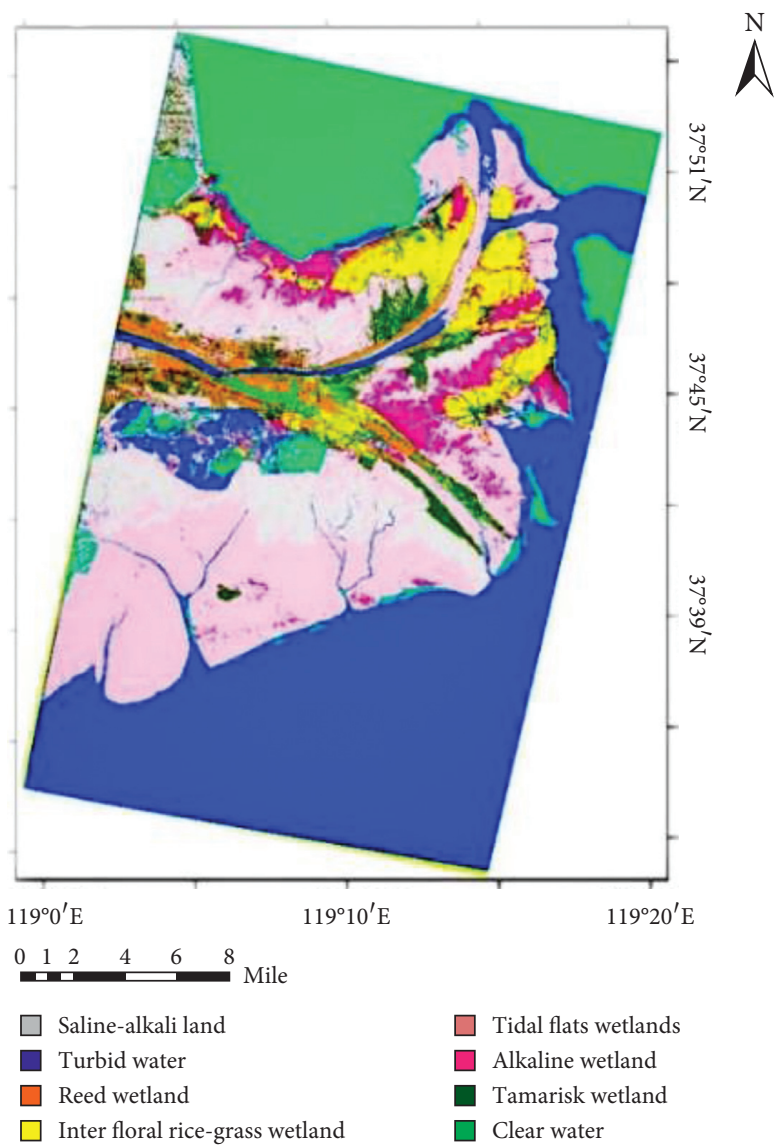

FIGURE 11: SVM classification result of hyperspectral remotesensing images.

The local zooming figure of wetland classification results in the study area obtained by using the SVM classification method and the MRF classification method is shown in Figure 12.

Comparing the classification result maps of the two methods, in general, both methods can distinguish the wetland types in the study area, but the classification result map of the SVM method has small particles in the details. For example, Figure 12(a) exists on the tidal flat wetland with small patches of Alkaline wetland, and there are small particles at the boundary between turbid water and clear water in Figure 12(b). In the result map of hyperspectral remote-sensing image classification based on MRF, the patch effect is greatly reduced. For example, there are no small particles in Figure 12(c) and (d).

3.4.2. Comparison of Classification Accuracy. The above verification points are used to evaluate the accuracy of SVM classification results and MRF-based hyperspectral remotesensing image classification results. The results are shown in Table 11.

Through the analysis of the overall classification accuracy, classification accuracy based on MRF reached $93.7286 \%$, the Kappa coefficient was 0.9119 , which was $3.9672 \%$ higher than the SVM method, and the Kappa 

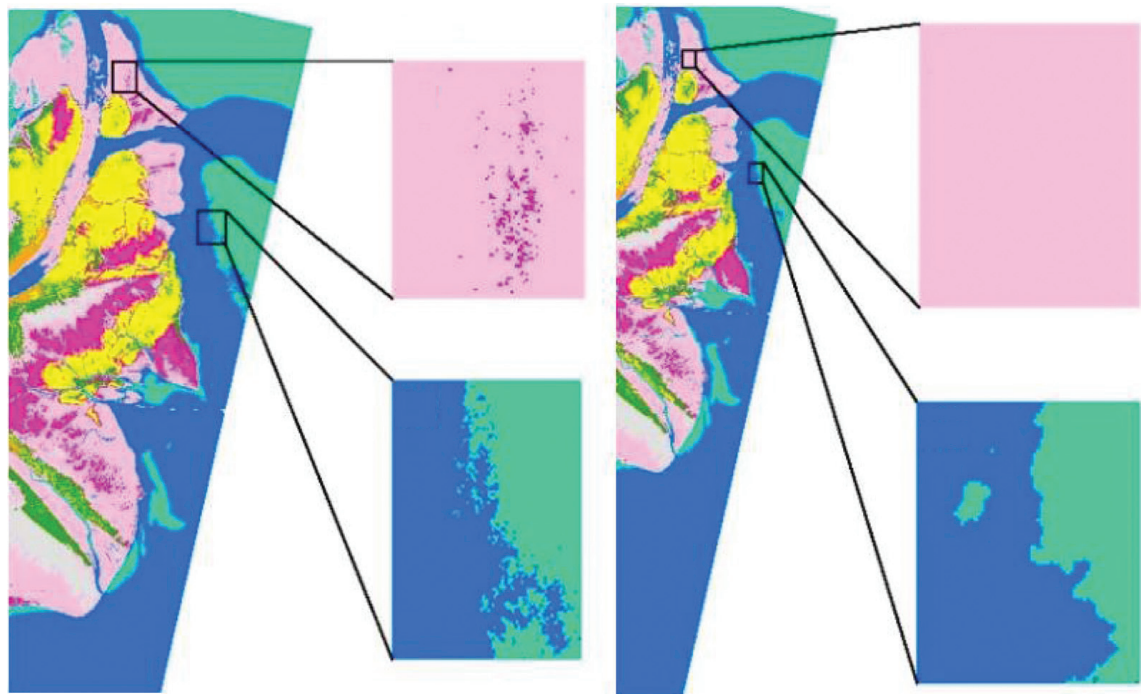

FIGURE 12: Local enlarged view (above: SVM classification method; below: MRF classification method).

TABLE 11: Classification accuracy evaluation table.

\begin{tabular}{lcccc}
\hline \multirow{2}{*}{ Feature category } & \multicolumn{2}{c}{ SVM classification results } & \multicolumn{2}{c}{$\begin{array}{c}\text { Based on MRF classification results } \\
\text { UA (\%) }\end{array}$} \\
\hline Turbid water & PA (\%) & UA (\%) & PA (\%) & 96.6 \\
Saline-alkali land & 97.84 & 92.96 & 81.71 & 94.53 \\
Tidal flats wetlands & 75.61 & 91.18 & 97.1 & 90.95 \\
Interfloral rice-grass wetland & 96.62 & 79.68 & 92.98 & 92.1 \\
Clear water & 87.72 & 96.15 & 89.84 & 96.15 \\
Reed wetland & 82.35 & 99.45 & 91.89 & 78.7 \\
Tamarisk wetland & 69.39 & & 71.43 & 96.4 \\
Alkaline wetland & 76.92 & & 82.61 & 93.13 \\
OA (\%) & 95.00 & & & 93.06 \\
Kappa & & 89.7614 & & 0.9119 \\
\hline
\end{tabular}

TABLE 12: Statistics of classification results of the study area.

\begin{tabular}{lcc}
\hline Wetland type & Area ratio $(\%)$ & Area $\left(\mathrm{km}^{2}\right)$ \\
\hline Clear water & 20.76 & 187.19 \\
Saline-alkali land & 7.40 & 66.72 \\
Tidal flats wetlands & 21.63 & 195.01 \\
Turbid water & 33.14 & 298.86 \\
Reed wetland & 3.92 & 35.32 \\
Alkaline wetland & 3.75 & 33.82 \\
Tamarisk wetland & 3.82 & 34.47 \\
Interfloral rice-grass wetland & 5.58 & 50.35 \\
\hline
\end{tabular}

coefficient was 0.042 higher. The SVM classification method of the overall classification accuracy will not only be influenced by the quality of the training sample, and its classification results could exist plaque effect. The main reason is this kind of method in the process of classification is mostly in isolation of each pixel gray value, ignoring the structural image gray space distribution; the same feature area often is subdivided into many kind of pixel mixed area [54]. The MRF-based hyperspectral remote-sensing image classification method combines spatial features and considers the constraints between regions, which makes up for the shortcomings of traditional supervised classification methods that only use the spectral features of pixels for classification. Moreover, traditional supervised classification methods need to rely more on training samples. When there are fewer samples or no training samples, the MRF-based classification method can better show its advantages. Analyzing each category, the classification accuracy of the 8 wetland types has been improved to varying degrees. 
3.4.3. Classification Result Statistics. The wetland type and area statistics are performed on the MRF classification results of the study area, and the spatial distribution characteristics of each wetland are analyzed accordingly. The resulting statistical table is shown in Table 12.

In the study area, the order of area from largest to smallest is turbid water, tidal flat wetland, clear water, salinealkali land, tamarisk wetland, interfloral rice-grass wetland, reed wetland, and alkaline wetland. Among them, the northern sea area of the study area has low sand content, mostly clear water bodies. Yellow River and the southern sea area of the study area have high sand content, mostly turbid water bodies. Tidal flat wetlands are generally distributed along the coast, and saline-alkali land is distributed inland next to tidal flat wetlands. Planted wetlands and interfloral rice-grass wetlands are distributed along the coast and mostly grown in areas with higher salinity. Interfloral ricegrass wetlands are the most widely distributed vegetation among the four vegetation wetlands. Reed wetlands are distributed along both banks of the river channel, including both the current river channel and the old river channel before the change of the Yellow River. According to the classification results, there are fewer reeds on both sides of the old river channel, which is similar to the reed growing mainly in soil moisture. Larger areas are related; tamarisk wetlands are mostly distributed on both banks of old rivers and next to reeds in the middle and lower reaches of the Yellow River. Alkaline wetlands are distributed near salinealkali soils and have strong saline-tolerant capacity. They are both in wet areas and heavy saline-alkali areas with extremely poor soil and can grow and develop normally.

\section{Conclusion}

Taking the wetland at the mouth of the Yellow River as the research area and the hyperspectral remote-sensing image of "Zhuhai One" as the main data source, this paper proposes to apply Markov random airport to the classification of hyperspectral wetland and designs experiments for analysis. The main conclusions of this article are

(1) By comparing the spectral features of the original image and the transformed image, the spectral feature enhancement method of the hyperspectral remote-sensing image, namely, logarithmic transformation, is determined. Logarithmic transformation can enhance the spectral difference between wetland features. The original image and the transformed image data are analyzed by subjective, objective evaluation, and categorization. The variance value of logarithmic transformation is 100 times that of the original image and derivative transformation image, and the classification separability is more than 1.999, which contains much information, and has high classification separability.

(2) The hyperspectral image classification method based on Markov random field was used to classify the study area. Through experimental verification, this method obtained good classification results. The results show that not only the coupling coefficient but also the initial value of the model has great influence on the classification results. When the coupling coefficient is less than 1 , the edge effect of the classification results is better, but the corresponding salt and pepper phenomenon will occur. When the coupling coefficient is greater than 1 , the regional connectivity is good, but some high-frequency information will be ignored accordingly. The setting of the initial value in the model is affected by the area of the study and the number of categories in the study. The larger the area and the more categories are, the larger the initial value will be. When the initial classification is 50 , the best result will be obtained.

Finally, the classification results are compared between the traditional classification SVM method and the method proposed in this paper. Through accuracy evaluation, the overall classification accuracy of this method has reached $93.7286 \%$, the Kappa coefficient is 0.9119 , which is $3.9672 \%$ higher than the traditional classification method, and the Kappa coefficient is increased by 0.042 . The classification method on MRF, combined with spatial features and considering the constraints between regions, makes up for the shortcomings of traditional supervised classification methods that only use the spectral characteristics of pixels for classification, and traditional supervised classification methods require more reliance training samples. When there are few or no training samples, the MRF-based classification method can better show its advantages.

\section{Data Availability}

No data were used to support the findings of the study.

\section{Conflicts of Interest}

The authors declare no conflicts of interest regarding this paper.

\section{Acknowledgments}

This work was supported by National Key Research and Development Program (2019YFE0126700).

\section{References}

[1] M A (Assessment, Millennium Ecosystem), Ecosystems and Human Well-Being:wetlands and Water, p. 5, World Resources Institute, Washington, DC, USA, 2005.

[2] Z. Wang, J. Wu, M. Madden, and D. Mao, "China's wetlands: conservation plans and policy impacts," Ambio, vol. 41, no. 7, pp. 782-786, 2012.

[3] D. Mao, Z. Wang, B. Du, L. Li, Y. Tian, and M. Jia, "National wetland mapping in China: a new product resulting from object-based and hierarchical classification of Landsat 8 OLI images," ISPRS-J Photogramm Remote Sens.vol. 164, pp. 1125, 2020. 
[4] C. Chen, Y. Ma, and G. B. Ren, "A convolutional neural network with fletcher-reeves algorithm for hyperspectral image classification," Remote Sensing, vol. 11, no. 11, 2019.

[5] S. Asselen, P. H. Verburg, J. E. Vermaat, and J. H. Janse, "Drivers of wetland conver-sion:a global meta-analysis," PLoS One, vol. 8, Article ID 381292, 2013.

[6] M. Kirwan and P. Megonigal, "Tidal wetland stability in the face of human impacts and sea-level rise," Nature, vol. 504, pp. 53-60, 2013.

[7] D. Mao, Z. Wang, J. Wu et al., "China's wetlands loss to urban expansion," Land Degradation \& Development, vol. 29, pp. 2644-2657, 2018a.

[8] A. M. Nahlik and M. S. Fennessy, "Carbon storage in US wetlands," Nature Communications, vol. 7, p. 13835, 2016.

[9] P. Zhu and P. Gong, "Suitability mapping of global wetland areas and validation with remotely sensed data," Science China Earth Sciences, vol. 57, no. 10, pp. 2283-2292, 2014.

[10] Q. Zhu, C. Peng, H. Chen et al., "Estimating global natural wetland methane emissions using process modelling: spatiotemporal patterns and contributions to atmospheric methane fluctuations," Global Ecology and Biogeography, vol. 24, pp. 959-972, 2015.

[11] C. C. De Araujo Barbosa, P. M. Atkinson, and J. A. Dearing, "Remote sensing of ecosystem services: a systematicreview," Ecological Indicators, vol. 52, pp. 430-443, 2015.

[12] M. Hussain, D. Chen, A. Cheng, H. Wei, and D. Stanley, "Changedetection from remotely sensed images: from pixelbasedto object-based approaches," ISPRS J Photogramm RemoteSens, vol. 80, pp. 91-106, 2013.

[13] D. Lu, G. Li, and E. Moran, "Current situation and needs ofchange detection techniques," International Journal Image Data Fusion, vol. 5, pp. 13-38, 2014.

[14] A. Singh, "Review article digital change detection tech-niques using remotely-sensed data," International Journal of Remote Sensing, vol. 10, pp. 989-1003, 1989.

[15] J. Zhang, "Multi-source remote sensing data fusion: statusand trends," International Journal of Image Data Fusion, vol. 1, pp. 5-24, 2010.

[16] A. Sánchez-Espinosa and C. Schrder, "Land use and land cover mapping in wetlands one step closer to theground: sentinel-2 versus landsat 8," Journal of Environmental Management, vol. 247, pp. 484-498, 2019.

[17] J. Zhao, L. Yu, Y. . Xu, H. Ren, X. Huang, and P. Gong, "Exploring the addition of Landsat 8 thermal band inlandcover mapping," International Journal of Remote Sensing, vol. 40, pp. 4544-4559, 2019.

[18] X. Zhu, Y. . Hou, Q. Weng, and L. Chen, "Integrating UA V optical imagery and LiDAR data for assessing thespatial relationship between mangrove and inundation across a subtropical estuarine wetland," ISPRS J.Photogramm. Remote Sens.vol. 149, pp. 146-156, 2019.

[19] R. A. Araya-López, J. Lopatin, F. E. Fassnacht, and H. J. Hernández, "Monitoring Andean high altitude wetlandsin central Chile with seasonal optical data: a comparison between Worldview-2 and Sentinel-2 imagery," ISPRS Journal of Photogrammetry and Remote Sensing, vol. 145, pp. 213-224, 2018.

[20] M. Yasir, H. Sheng, H. Fan et al., "Automatic coastline extraction and changes analysis using remote sensing and GIS technology," IEEE Access, vol. 8, pp. 180156-180170, 2020.

[21] X. Wang, X. Gao, Y. . Zhang et al., "Land-Cover classificationof coastal wetlands using the RF algorithm for Worldview-2 and Landsat 8 images," Remote Sensing, vol. 11, p. 1927, 2019.
[22] T. Abeysinghe, A. Simic Milas, K. Arend et al., "Mappinginvasive phragmites australis in the old woman creek estuary using UA V remote sensing and machinelearning classifiers," Remote Sensing, vol. 11, p. 1380, 2019.

[23] J. Cao, W. Leng, K. Liu, L. Liu, Z. He, and Y. Zhu, "Objectbased mangrove species classification usingunmanned aerial vehicle hyperspectral images and digital surface models," Remote Sensing, vol. 10, p. 89, 2018.

[24] J. Zhao, S. Liu, J. Wan, M. Yasir, and H. Li, "Change detection method of high resolution remote sensing image based on D-S evidence theory feature fusion," IEEE Access, vol. 9, pp. 4673-4687, 2021.

[25] M. Yasir, S. Hui, Z. Hongxia et al., "A spatiotemporal change detection analysis of coastline data in qingdao, east china," Scientific Programming, vol. 2021, Article ID 6632450, 10 pages, 2021.

[26] M. S. Hossain, M. Yasir, P. Wang et al., "Automatic shoreline extraction and change detection: a study on the southeast coast of Bangladesh," Marine Geology, vol. 441, Article ID 106628, 2021.

[27] E. Belluco, M. Camuffo, S. Ferrari et al., "Mapping salt-marsh vegetation by multispectral and hyperspectral remote sensing," Remote Sensing of Environment, vol. 105, pp. 54-67, 2006.

[28] A. Barducci, D. Guzzi, P. Marcoionni, and I. Pippi, "Aerospace wetland monitoring by hyperspectral imagingsensors: a case study in the coastal zone of San Rossore Natural Park," Journal of Environmental Management, vol. 90, pp. 22782286, 2009.

[29] M. Guo, J. Li, C. Sheng, J. Xu, and L. Wu, "A review of wetland remote sensing," Sensors, vol. 17, no. 4, p. 777, 2017.

[30] P. Cong, K. Chen, L. Qu, and J. Han, "Dynamic changes in the wetland landscape pattern of the Yellow River delta from 1976 to 2016 based on satellite data," Chinese Geographical Science, vol. 29, no. 3, pp. 372-381, 2019.

[31] Y. Chen, China Wetlands Research, JilinScience and Technology Publishing House, Changchun, China, inChinese, 1995.

[32] X. Fu, G. H. Liu, S. Y. Chai, C. Huang, and F. D. Li, "Spatialtemporal analysis ofwetland landscape pattern under the influence of artificialdykes in the Yellow River delta," Chinese Journal of Popula-tion Resources and Environment, vol. 11, no. 2, 2013.

[33] Y. Liu, G. Wang, and F. Zhang, "Spa-tio-temporal dynamic patterns of rural area development ineastern coastal China," Chinese Geographical Science, vol. 23, no. 2, pp. 173-181, 2013.

[34] J. W. Dong, X. M. Xiao, M. A. Menarguez et al., "Mappingpaddy rice planting area in northeastern Asia with Landsat 8images, phenology-based algorithm and Google Earth Engine," Remote Sensing of Environment, vol. 185, pp. 142-154, 2016.

[35] M. J. Escorihuel and P. Quintana-Seguí, "Comparison of remotesensing and simulated soil moisture datasets in Mediterraneanlandscapes," Remote Sensing of Environment, vol. 180, pp. 99-114, 2016.

[36] J. T. Liu, Q. L. Feng, J. H. Gong, J. P. Zhou, and Y. Li, "Landcover classifica-tion of the Yellow River Delta wetland based on multipleend-member spectral mixture analysis and a Random Forestclassifier," International Journal of Remote Sensing, vol. 37, no. 8, pp. 1845-1867, 2016.

[37] X. Zong, G. Liu, Y. Qiao, and S. Lin, "Study ondynamic changes of wetland landscape pattern in YellowRiver Delta," Journal of Geo-Information Science, vol. 11, no. 1, pp. 91-97, 2009, in Chinese. 
[38] H. Song, X. Mou, and X. Liu, "The impact of human disturbance activities on the growth of typical vegetation in the coastal wetlands of the Yellow River Delta," Journal of Ecological Environment, vol. 28, no. 12, pp. 2307-2314, 2019, in Chinese.

[39] Y. X. Zou, J. Cheng, K. Liu et al., "The contents of carbon and nitrogen of different forms and distribution of ammonia oxidizing prokaryotes in soils of ancient yellow river," Wetland Science, vol. 6, pp. 752-758, 2016.

[40] C. Wang, Z. Liu, and C. Yan, "Experimental study on feature selection of imaging spectral data and wheat variety identification," Journal of Remote Sensing, vol. 2, pp. 249-255, 2006, in Chinese.

[41] H.. Xu, Research on Wetland Remote Sensing Classification and Ecosystem Health Assessment Based on Support Vector machine, Shenyang Agricultural University, Shenyang, China, 2017, in Chinese.

[42] Q. Tong, B. Zhang, and L. Zheng, Hyperspectral Remote Sensing-Principle Technology and application, pp. 136-146, Higher Education Press, Beijin, Chinas, 2006, in Chinese.

[43] L. Zhao, L. Guo, and J. Xie, "Scene description of conditional random field model," Journal of Image and Graphics, vol. 18, no. 3, pp. 271-276, 2013, in Chinese.

[44] C.. Liu, Application Research of Region-Based Markov Random Field in High-Resolution Remote Sensing Image classification, Yunnan Normal University, Yunnan, China, 2015, in Chinese.

[45] C. Liu, Research on Application of Region-Based Markov Random Field in Classification of High-Resolution Remote Sensing Images, Yunnan Normal University, Kunming, China, 2015.

[46] Di. Xu, Application Research of Markov Random Field in Image Segmentation method, Harbin Institute of Technology, Harbin, China, 2013, in Chinese.

[47] S. Ding, B. Qi, and H. Tan, "Summary of support vector machine theory and algorithm research," Journal of University of Electronic Science and Technology of China, vol. 40, no. 1, pp. 2-10, 2011, in Chinese.

[48] Y. Wu, Y. Zhou, and Y. Long, "Detection of small targets in hyperspectral remote sensing images based on adaptive parameter support vector machines," Acta Optics, vol. 35, no. 9, pp. 330-339, 2015, in Chinese.

[49] G. Yang, X. Yu, W. Liu, and W. Chen, "Research on classification methods for hyperspectral remote sensing images," Bulletin of Surveying and Mapping, vol. 10, pp. 17-20, 2007.

[50] G. Yang, X. Yu, W. Liu et al., "Research on classification methods for hyperspectral remote sensing images," Bulletin of Surveying and Mapping, vol. 10, pp. 17-20, 2007, in Chinese.

[51] P. Du, J. Xia, C. Xue, K. Tan, H. Su, and K. Bao, "Research progress of hyperspectral remote sensing image classification," Journal of Remote Sensing, vol. 20, no. 2, pp. 236-256, 2016, in Chinese.

[52] L.. Yang, Comparative Study on Hyperspectral Estimation Methods of Soil Characteristics in the Source Area of the Three Rivers, Qinghai Normal University, Xining, China, 2016, in Chinese.

[53] J.. Li, Research on Dimensionality Reduction and Classification Methods of Hyperspectral Remote Sensing images, Central South University, Changsha, China, 2012, in Chinese.

[54] C. Xie, A. Wang, and P. Liu, "The application of multi-scale Markov random field in the classification of urban features based on high-resolution synthetic aperture radar images," Digital Communication World, vol. 05, pp. 12-15, 2016, in Chinese. 